\title{
Preparation of Blend Hydrophilic Polyetherimide-Cellulose Acetate Hollow Fiber Membrane for Oily Wastewater Treatment
}

\author{
Moslem Nazarian, Amir Mansourizadeh \& Mehran Abbasi \\ Department of Chemical Engineering, Gachsaran branch, Islamic Azad University, \\ Gachsaran, Iran
}

Submitted: 22/03/2019. Revised edition: 2/07/2019. Accepted: 11/07/2019. Available online: 20/09/2019

\begin{abstract}
Membrane separation is known as an efficient technique for oily wastewater treatment. In the present study, cellulose acetate (CA) was introduced into the polyetherimide (PEI) solution in order to enhance hydrophilicity and the membrane structure for oil-water separation. The hollow fiber membranes were prepared via a phase-inversion process. The membranes were characterized by $\mathrm{N}_{2}$ permeation test, water contact angle, pure water flux and field emission scanning electron microscopy (FESEM). The blend PEI-CA membrane presented larger finger-likes morphology with a thicker outer skin layer. From $\mathrm{N}_{2}$ permeation test, the blend membrane showed effective surface porosity of $697 \mathrm{~m}^{-1}$ and mean pore size of $4.5 \mathrm{~nm}$. The higher water flux and lower resistance of the blend PEI-CA membrane were related to the higher hydrophilicity and the open structure. Due to small pore sizes and enhanced hydrophilicity, the blend membrane showed a stable oil rejection of over $98 \%$ and water flux of $18 \mathrm{~L} / \mathrm{m}^{2} \mathrm{~h}$ after $100 \mathrm{~min}$ of the separation operation. The developed PEI-CA membrane can potentially be applied in petrochemical and refinery industries for oily wastewater treatment.
\end{abstract}

Keywords: Blend PEI hollow fiber membrane, Cellulose acetate, Characterization, Oily wastewater

\subsection{INTRODUCTION}

A competent separation technology is required in order to reduce environmental impacts caused by oily wastewater produced in oil and gas, petrochemical, metallurgical, pharmaceutical and food industries. Membrane separation technology provides properties such as energy efficiency, easy processing and low operation and maintenance cost, which has been developed as a proficient system for oily wastewater treatment [1-6]. Polymeric membranes have been widely designed and developed for wastewater treatment due to their well establishment and excellent long term stability [7].

Trade-off relationship between permeability and selectivity is one of the major issues in the use of polymeric membranes in wastewater treatment. Moreover, fouling and scaling can lead to a sufficient flux reduction and hinders long-term operation of the membranes in a practical wastewater treatment system. Therefore, it is required to improve the membrane structure and properties via different strategies of modification.

Surface hydrophilization is one of the remarkable approaches for membrane antifouling during oily wastewater treatment. It is worth mentioning that by using highly hydrophilic membranes, a decrease in the deposition of oil on the membrane surface can result in reduction of membrane fouling and enhancement of water flux [8-10]. Blending with hydrophilic polymers is a simple 
modification method to enhance surface hydrophilicity, which is an economic single step membrane formation process. Cellulose acetate (CA) with good hydrophilicity can be an alternative to prepare blend polymeric membranes with improved performance. Indeed, CA and its derivatives are suitable materials for fabrication of membranes for water and wastewater treatment thanks to the properties such as good biocompatibility, high hydrophilicity, suitable resistance to chlorine, nontoxic nature and low cost $[11,12]$.

El-Gendi et al. [13] fabricated blend polyvinylchloride/cellulose acetate (PVC/CA) membranes, using a wet phase inversion technique, for seawater reverse osmosis (SWRO) process. Using 3\% CA and 16\% PVC in the polymer solution resulted in the membrane with high mechanical strength and good desalination performance. The developed membrane showed sufficient rejection of $98-99 \%$ under different feed concentrations. The removal of heavy metal ions and humic acid by $\mathrm{CA}$ and poly (methyl vinyl ether-alt-maleic acid) (PMVEMA) blend membranes were investigated by Lavanya et al. [14]. The blend membranes were very effective in removing heavy metal ions and humic acid simultaneously. It was suggested that the PMVEMA modified CA membranes can be a promising alternative in enhancing the hydrophilicity, permeability and antifouling properties. In another study, CA was blended with polyethersulfone (PES) to enhance hydrophilicity and antifouling property by using N,N-dimethylacetamide (DMAc) as the polymers solvent [15]. The addition of CA in the solution, resulted in the formation of larger finger-like macrovoids and higher surface porosity, which resulted in higher pure water flux and better antifouling performance compared to the plain membrane. From TGA analysis, it was found that the blend CA-PES membrane possess good thermal stability below $270{ }^{\circ} \mathrm{C}$. CA and cellulose acetate phthalate (CAP) were used as additives in the polymer solution to prepare polyphenylsulfone (PPSU) hollow fiber membranes for arsenic removal from water [16]. It was found that the hollow fiber membrane prepared by addition of 5 wt $\%$ of CAP in PPSU, has higher removal efficiency compared to the membrane prepared by $5 \mathrm{wt} \%$ of CA in PPSU. The removal efficiency of arsenic was $34 \%$ and $41 \%$ for the membranes prepared by CA and CAP, respectively. In addition, the blend membrane permeability was 44.42 $\mathrm{L} / \mathrm{m}^{2} \mathrm{~h}$ and $40.11 \mathrm{~L} / \mathrm{m}^{2} \mathrm{~h}$ for the membranes prepared by $\mathrm{CA}$ and CAP, respectively.

Epoxidated polyethersulfone (EPES) incorporated CA ultrafiltration membranes were prepared by a phase separation process [17]. Addition of EPES in the solution, resulted in the formation of thin surface layer and spongy sub-layer for the blend CA/EPES membrane. The blend membrane presented improved separation efficiency for commercially important proteins such as bovine serum albumin, egg albumin, pepsin and trypsin, compared to the CA membrane. Rahimpour and Madaeni [18] prepared PES/CAP blend ultrafiltration membranes for milk concentration. The pure water flux and milk water permeation of the prepared membranes were increased by addition of $20 \%$ CAP in the casting solution. However, further addition of CAP sharply decreased the membrane performance.

Since pure CA hollow fiber membranes possess several drawbacks such as lack of chemical, biological and mechanical stability, as they are 
very brittle in nature, blending $\mathrm{CA}$ with different polymers can be a promising alternative to enhance the properties of the membrane for oily wastewater treatment. In the present study, blend ultrafiltration polyetherimide (PEI)-CA hollow fiber membranes were prepared via a phase separation process. The prepared membranes were characterized by the experiments such as $\mathrm{N}_{2}$ permeation, water contact angle, field emission scanning electron microscopy (FESEM), and pure water flux. Treatment of a simulated oily wastewater was conducted through an ultrafiltration system.

\subsection{METHODS}

\subsection{Materials}

PEI (Ultem $\left.{ }^{\circledR} 1000\right)$ pellets were supplied from General Electric Company and used as the base polymer. Cellulose acetate $(38.9$ wt $\%$ cellulose content) with number average molecular weight of 30,000, was used as the blending polymer, provided by Sigma-Aldrich. 1-methyl-2pyrrolidone (NMP, >99.5\%) was supplied by MERCK and used as the polymer solvent without further purification. Glycerol $(\geq 99.5 \%$, SigmaAldrich) was used as the pore forming additive in the polymer solution. Ethanol was purchased from SigmaAldrich and used for post-treating of the hollow fiber membranes. Kerosene (97\% purity, Fluka) was used to prepare simulated oily wastewater for the ultrafiltration experiment.

\subsection{Preparation of Porous Hollow Fiber Membranes}

In order to prepare the solutions for hollow fiber membrane fabrication, the polymers were dried in a vacuum oven at $60{ }^{\circ} \mathrm{C}$ overnight. The plain spinning solution of $14 \mathrm{wt} \%$ solid PEI and 3 wt.\% glycerol balanced with NMP was prepared under stirring at $60{ }^{\circ} \mathrm{C}$ until a homogeneous solution was achieved. The modified solution was prepared by CA, which contains 20 wt. $\%$ of the solid polymer in the solution. Before spinning hollow fiber membranes, the resulting solutions were degassed under 15 min sonication and then kept $24 \mathrm{~h}$ at room temperature. The spinning process for hollow fiber membrane fabrication was explained elsewhere [19]. Table 1 lists the detailed spinning parameters. The resulting hollow fiber membranes were thoroughly immersed in distilled water for 3 days to remove the residual solvent and glycerol. Before drying the hollow fibers at room temperature, post treatment was performed by 15 min immersion of the fibers in pure ethanol to minimize shrinkage and pores collapse.

Table 1 Parameters of hollow fiber spinning

\begin{tabular}{ll}
\hline Parameter & Value \\
\hline Dope extrusion $(\mathrm{ml} / \mathrm{min})$ & 2.0 \\
Bore fluid $(\mathrm{ml} / \mathrm{min})$ & 0.5 \\
Bore fluid composition & $\mathrm{NMP} / \mathrm{H}_{2} \mathrm{O}$ \\
(wt.\%) & $70 / 30$ \\
External coagulant & Tap water \\
Air gap distance $(\mathrm{cm})$ & 0.5 \\
od/id $(\mathrm{mm})$ & $0.7 / 0.3$ \\
Spinning dope temp. & 25 \\
$\left({ }^{\circ} \mathrm{C}\right)$ & \\
Coagulation bath temp. & 25 \\
$\left({ }^{\circ} \mathrm{C}\right)$ & \\
\hline
\end{tabular}

\subsection{Characterization of Hollow Fiber Membranes}

Morphology of the prepared membranes was examined by field emission scanning electron microscopy (FESEM) (Hitachi S-4700). The FESEM images of cross-sectional, 
internal and external surfaces of the hollow fibers were taken at different magnifications.

$\mathrm{N}_{2}$ permeation test was used to examine the mean pore size and effective surface porosity over pore length of the prepared membranes. Generally, overall gas permeation rate through a porous membrane can be in agreement with combination of Poiseuille and Knudsen flows [20]. Therefore, in view of cylindrical pores in the outer skin layer of the porous membranes, the gas permeance can be calculated as below equation:

$J_{A}=\frac{2 r p \varepsilon}{3 R T L p}\left(\left(\frac{8 R T}{\pi M}\right)^{0.5}\right)+\frac{r_{p}^{2}}{8 \mu R T} \frac{\varepsilon}{L_{P}} \bar{P}$ or

$J_{A}=K_{0}+P_{0} \bar{P}$

where $\mathrm{J}_{\mathrm{A}}$ is the gas permeance $\left(\mathrm{mol} / \mathrm{m}^{2}\right.$ $\mathrm{s} \mathrm{Pa}) ; r_{p}$ and $\mathrm{L}_{\mathrm{p}}$ are pore radius and effective pore length, respectively (m); $\varepsilon$ is surface porosity; $\mathrm{R}$ is universal gas constant $8.314(\mathrm{~J} / \mathrm{mol} \mathrm{K}) ; \mu$ is gas viscosity $(\mathrm{kg} / \mathrm{m} \mathrm{s}) ; \mathrm{M}$ is gas molecular weight $(\mathrm{Kg} / \mathrm{mol})$; $\mathrm{T}$ is gas temperature (K); and $\bar{P}$ is mean pressure (Pa).

Based on Eq.(1), by plotting $\mathrm{J}_{\mathrm{A}}$ versus mean pressure, the intercept $\left(\mathrm{K}_{0}\right)$ and slope $\left(\mathrm{P}_{0}\right)$ of the permeance line can be measured to estimate mean pore size and effective surface porosity over pore length $\left(\varepsilon / L_{p}\right)$, as following Eqs.:

$r_{p}=5.33\left(\frac{P_{0}}{K_{0}}\right)\left(\frac{8 R T}{\pi \mu}\right)^{0.5}$

$\frac{\varepsilon}{L_{P}}=\frac{8 \mu R T P 0}{r_{p}^{2}}$

For measurement of outer surface water and oil contact angle, the membrane samples were dried in a drier at $60{ }^{\circ} \mathrm{C}$ for $12 \mathrm{~h}$. The sessile drop technique using a goniometer (model G1, Krüss GmbH, Hamburg, Germany) was applied to measure contact angle of the hollow fibers. For each membrane sample, the average value of contact angle was reported for ten various positions of the sample.

In order to evaluate the hydraulic resistance and permeate flux of the membranes, pure water flux experiment was conducted. In this experiment, the sell side of the membrane module was pressurized up to $600 \mathrm{kPa}$. Water flux $\left(\mathrm{J}_{\mathrm{w}}\right)$ at each pressure was calculated according to the following equation:

$$
J_{W}=V / A . \Delta t
$$

where $J_{w}$ is water flux $\left(\mathrm{L} / \mathrm{m}^{2} \mathrm{~h}\right) ; \mathrm{V}$ is the volume of permeate collected (L); $\Delta \mathrm{t}$ is the sampling time (h); and $\mathrm{A}$ is the outer surface area of the membrane $\left(\mathrm{m}^{2}\right)$.

Pure water flux of the membrane vs. trans-membrane pressure (TMP) was plotted to calculate the membrane hydraulic resistance $\left(\mathrm{R}_{\mathrm{m}}\right)$. The hydraulic resistance can be calculated by obtaining the slope of $J_{w}$ vs. TMP line, as shown below [2]:

$J_{W}=T M P / R_{m}$

In order to conduct oil-water separation, simulated oily wastewater was prepared by adding $500 \mathrm{mg}$ of kerosene into $1000 \mathrm{ml}$ of distilled water under constant stirring of 5000 $\mathrm{rpm}$. The resulting stable emulsion had oil droplets in the range of $0.5-1 \mu \mathrm{m}$ that was estimated using optical microscope (BHS-323, OLYMPUS Co., Ltd., Tokyo, Japan). After preparing the membrane modules with characteristics given in Table 2, a cross-flow experimental set-up was used for oil-water separation, as shown in Figure 1. The TMP was adjusted by the by-pass valve of the pump. The flow rate in the shell side of the membrane module was fixed at 200 $\mathrm{ml} / \mathrm{min}$ by a control valve, manually. The volume of permeate collected was 
used to measure the permeate flux. The applied pressure in the sell side of the module was fixed at $400 \mathrm{kPa}$. Oil concentrations in the feed and permeate were measured by a TOC (total organic carbon) analyzer (GE Analytical Instrument 500RL). The oil rejection of the membranes was calculated according to the below equation:

$$
R(\%)=\left(1-\frac{C_{p}}{C_{f}}\right) \times 100
$$

where $\mathrm{R}$ is the oil rejection, $\mathrm{C}_{\mathrm{p}}$ and $\mathrm{C}_{\mathrm{f}}$ $(\mathrm{mg} / \mathrm{l})$ are oil concentration in the permeate and feed, respectively.

After oil separation test, the hollow fiber membranes were carefully taken out of the module and immersed in ethanol for $15 \mathrm{~min}$ before drying at room temperature. Then the used membranes were characterized in terms of $\mathrm{N}_{2}$ permeance at $100 \mathrm{kPa}$, pure water flux at $400 \mathrm{kPa}$ and outer surface water contact angle.

Table 2 Membrane module characteristics

\begin{tabular}{ll}
\hline Module inner diameter $(\mathrm{mm})$ & 14 \\
Module length $(\mathrm{mm})$ & 280 \\
Effective fiber length $(\mathrm{mm})$ & 180 \\
Fiber outer diameter $(\mathrm{mm})$ & 0.65 \\
Fiber inner diameter $(\mathrm{mm})$ & 0.30 \\
No. of fibers & 20 \\
\hline
\end{tabular}

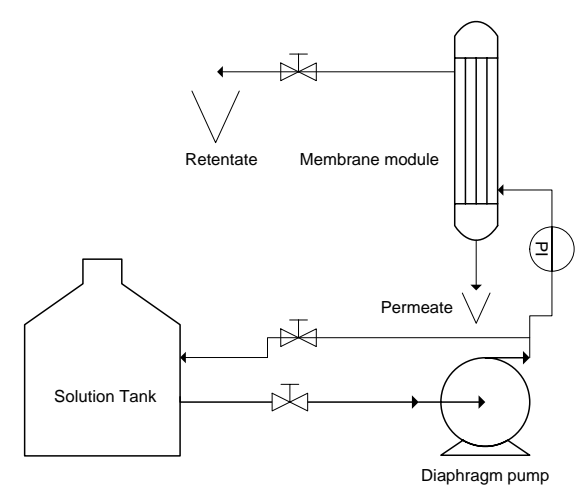

Figure 1 Schematic of experimental ultrafiltration system

\subsection{RESULTS AND DISCUSSION}

\subsection{Morphological Analysis of the Membranes}

FESEM images of cross-section, inner surface and outer surface of the prepared hollow fiber membranes are shown in Figure 2. The prepared membranes showed an average outer and inner diameters of 650 and 300 $\mu \mathrm{m}$, respectively. It can be said that the final membrane structure prepared by a phase-inversion process is controlled by thermodynamic and kinetic effects of the polymer solution [21, 22]. Thermodynamic instability of the solution can be achieved by addition of non-solvent additive which can enhance liquid-liquid phase separation. This results in a membrane with large finger-likes structure. In contrast, kinetic effect due to increase of the solution viscosity by additive can reduce mutual diffusion of solvent/water during phase-inversion process which results in sponge-like structure. For plain PEI membrane, by addition of $3 \%$ glycerol in the solution, it seems that the kinetic effect was overtaken by thermodynamic effect and a finger-like structure was produced, as shown in Figure 2(A1). At FESEM magnification of $50 \mathrm{~K}$, the outer skin of the plain membrane showed a good surface porosity which can be related to the narrow fingerlikes extended to the outer surface. An aqueous solution of $70 \%$ NMP was applied as the bore fluid in order to remove inner surface and minimize the membrane resistance. In fact, in this case, the delay solidification results in an inner skinless layer with microporous structure. 

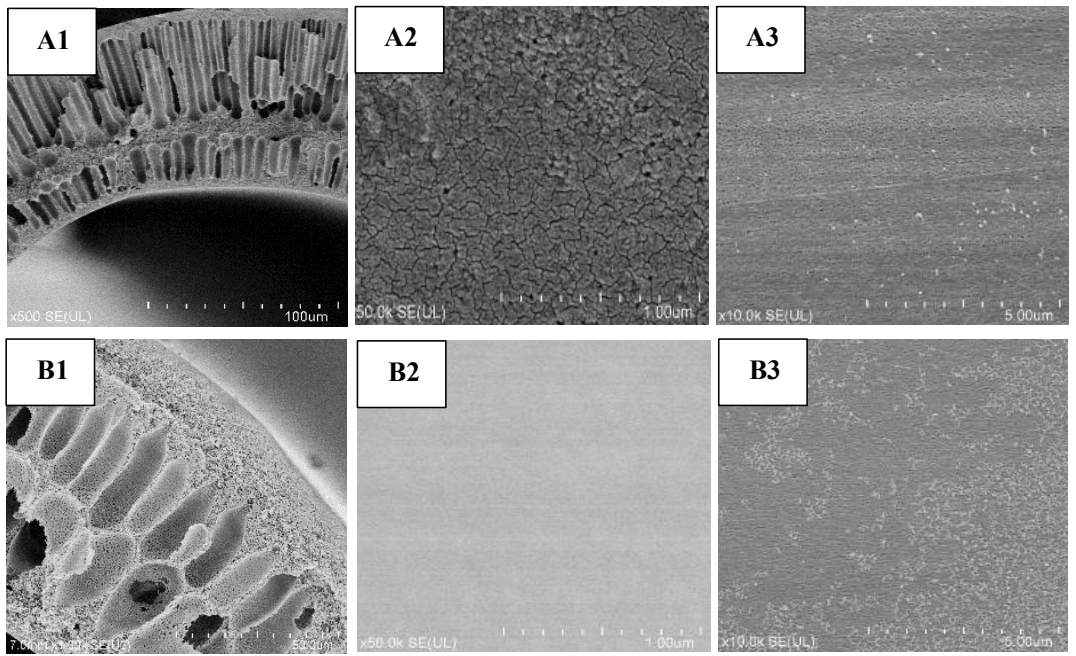

Figure 2 FESEM micrographs of hollow fiber membranes: (A) plain membrane; (B) blend membrane; (1) cross-section; (2) outer surface; and (3) inner surface

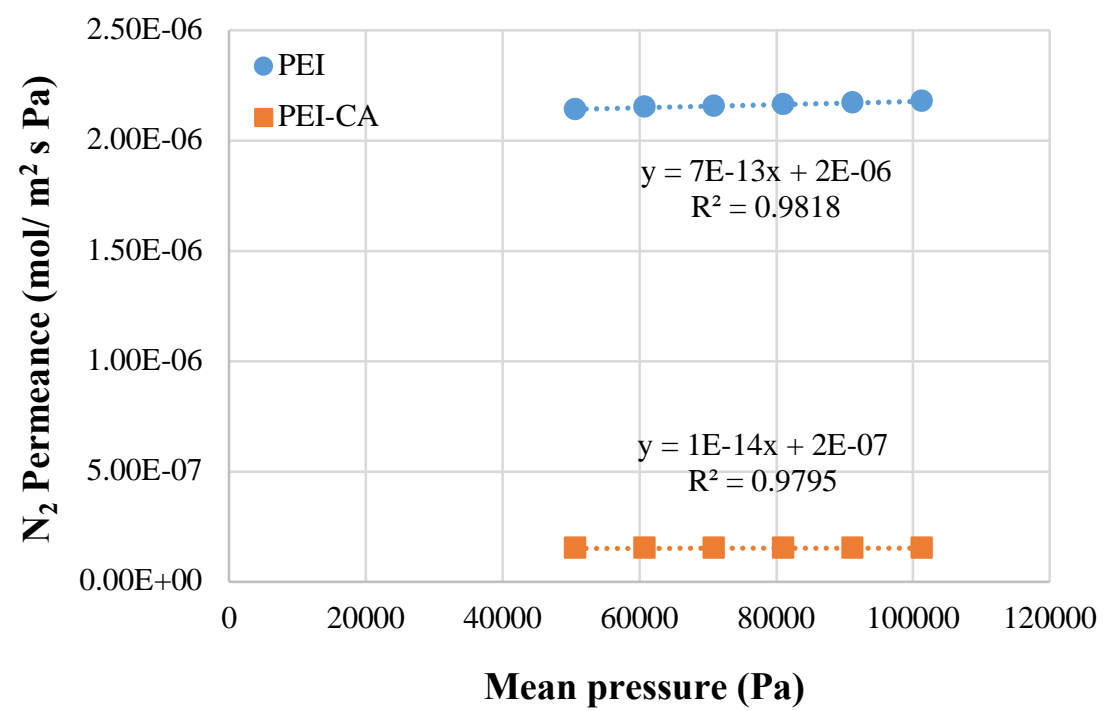

Figure $3 \mathrm{~N}_{2}$ permeance of the prepared hollow fiber membranes

For the blend PEI-CA membrane, a structure with larger finger-like cavities and a thick outer skin layer was formed as shown in Figure 2(B1). In fact, CA worked as a non-solvent in the solution and reduced thermodynamic stability of the solution. This effect resulted in a fast phase-inversion and generation of larger finger-likes. In addition, because of higher hydrophilicity and affinity of CA to water, fast solidification from outer surface resulted in formation of a thicker outer skin layer. As for inner surface morphology of the blend membrane, an inner surface with open structure was formed, similar to the plain membrane.

\subsection{Properties of Hollow Fiber Membranes}

In this study, $\mathrm{N}_{2}$ permeation test was used to estimate mean pore size and effective surface porosity of the membranes. $\mathrm{N}_{2}$ permeance of the membranes as a function of mean pressure is shown in Figure 3.

By increasing the mean pressure, a minimum variation was observed in $\mathrm{N}_{2}$ 
permeance of the blend membrane. This phenomenon indicates that the Knudsen flow controls gas transport through the surface pores of the blend membrane which confirms small nanoscale pore sizes. This result is in agreement with the FESEM images, as the prepared blend membrane with a thick outer skin layer could reduce the permeability and surface porosity. The plain membrane exhibited a considerably higher $\mathrm{N}_{2}$ permeance which can be attributed to the membrane morphology with thin skin layer. The larger slope of $\mathrm{N}_{2}$ permeance line for the plain membrane can confirm larger pore sizes on the outer surface compared to the blend membrane. By measuring the intercept and slope of the $\mathrm{N}_{2}$ permeance lines plotted in Figure 3, the mean pore size and the effective surface porosity over pore length was calculated according to Eqs. (2 and 3). The results of mean pore size and surface porosity are shown in Table 3. The blend membrane possesses mean pore size of $4.5 \mathrm{~nm}$ and a good surface porosity of $697 \mathrm{~m}^{-1}$.

Table 3 Properties of the prepared hollow fiber membranes

\begin{tabular}{|c|c|c|c|c|c|c|}
\hline $\begin{array}{l}\text { Hollow } \\
\text { fiber } \\
\text { membrane }\end{array}$ & $\begin{array}{c}\mathrm{N}_{2} \text { permeance } \\
\text { @ } 100 \mathrm{kPa} \\
(\mathrm{GPU})\end{array}$ & $\begin{array}{c}\text { Mean } \\
\text { pore size } \\
(\mathbf{n m})\end{array}$ & $\begin{array}{c}\text { Effective } \\
\text { surface } \\
\text { porosity } \\
\varepsilon / \mathbf{L}_{\mathbf{p}}\left(\mathbf{m}^{-1}\right)\end{array}$ & $\begin{array}{c}\text { Hydraulic } \\
\text { resistance } \\
\left(\mathbf{R}_{\mathbf{m}}\right) \\
\left(\mathbf{m}^{2} \mathbf{h} \text { bar } / \mathrm{L}\right)\end{array}$ & $\begin{array}{c}\text { Water } \\
\text { contact } \\
\text { angle }\left(^{\circ}\right)\end{array}$ & $\begin{array}{c}\text { Oil } \\
\text { contact } \\
\text { angle }\left(^{\circ}\right)\end{array}$ \\
\hline PEI & 7020 & 31 & 996 & 0.318 & $81.8 \pm 2.2$ & $92.6 \pm 1.6$ \\
\hline PEI-CA & 495 & 4.5 & 697 & 0.146 & $72.2 \pm 1.3$ & $104.3 \pm 3.2$ \\
\hline
\end{tabular}

Hydrophilicity of the PEI and PEICA membranes was estimated by measuring outer surface water contact angle. As shown in Table 3, by addition of CA in the PEI solution, the prepared blend membrane presented a relatively lower contact angle value of $72^{\circ}$. About $10^{\circ}$ decrease in the contact angle of the blend membrane can be related to the hydrophilic nature of CA [15]. Indeed, an improvement in the membrane hydrophilicity can result in enhancement of the water flux. In addition, the oil contact angle of the membranes was measured and shown in Table 3. The oil contact angle is relatively higher than water contact angle which confirms hydrophilicity of the membranes. In general, a hydrophilic surface has a low affinity with the organic liquids. The blend PEI-CA membrane showed $104^{\circ}$ oil contact angle which means it has a good potential for oil repellent during the oily wastewater treatment.
Water flux of the PEI and blend PEICA membranes as a function of TMP are shown in Figure 4. By measuring the slope of the water flux lines, hydraulic resistance of the membranes was calculated and the results are given in Table 3. By increasing TMP, a significant increase in the water flux was observed for the blend membrane, as shown in Figure 4. This can be related to enhanced hydrophilicity and the open finger-like structure of the blend membrane compared to the plain PEI membrane. It seems that the effect of surface porosity $\left(\mathrm{N}_{2}\right.$ permeability) was over taken by the effect of hydrophilicity. In addition, due to the larger surface pores of the plain membrane, pore collapsing at higher TMP is possible which may affect the flux. A similar water flux improvement was reported for blend polyether sulfone flat sheet membranes when 5 wt.\% of hydrophilic CA was added into the polymer dope [2]. As shown in 
Table 3, the hydraulic resistance of the blend membrane was considerably smaller than the resistance of the plain membrane. This can be associated to the improved structure of the blend membrane.

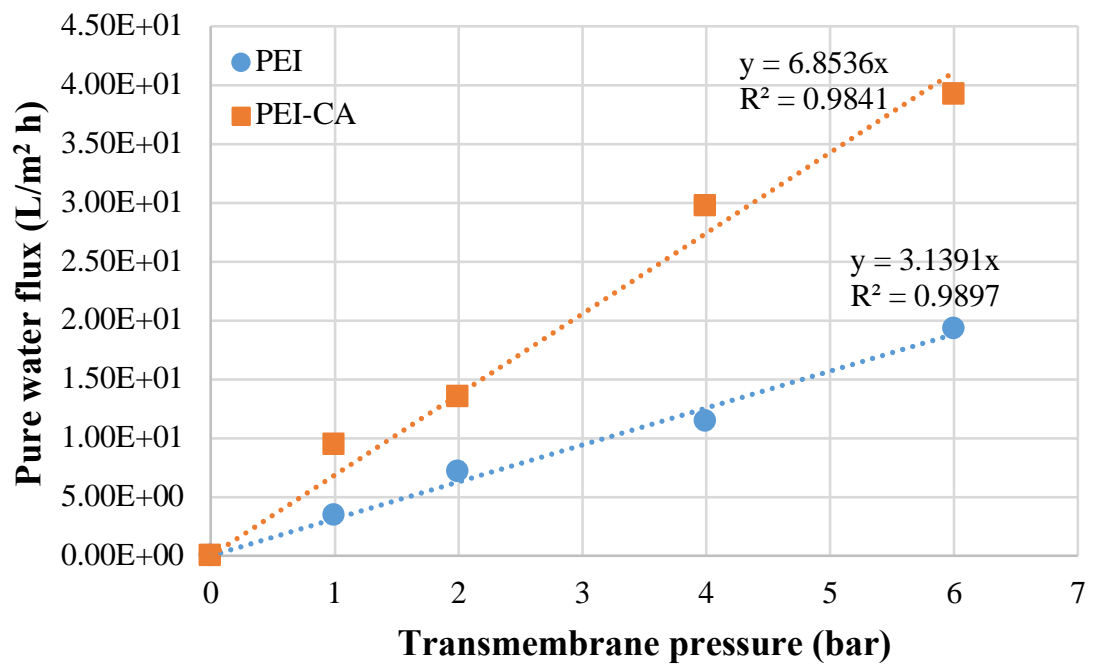

Figure 4 Pure water flux of the membranes as function of transmembrane pressure

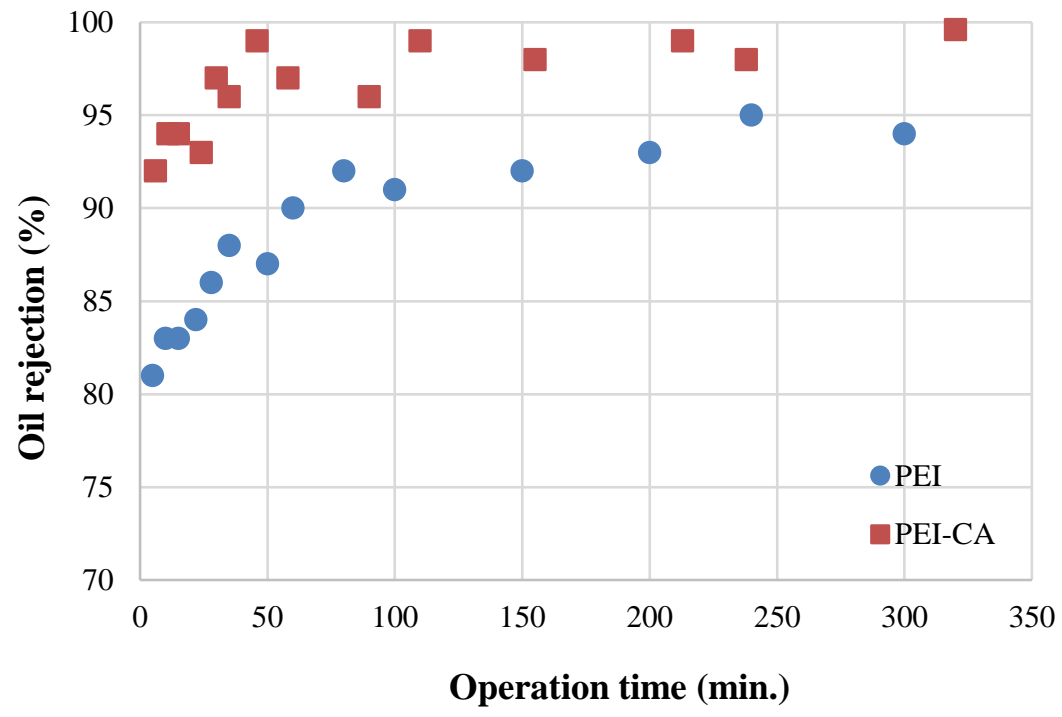

Figure 5 Oil rejection performance of the hollow fiber membranes

\subsection{Oil-water Performance of the Membranes}

To evaluate the separation performance of the membranes, oil rejection test was conducted through the cross-flow membrane separation system. The separation test was performed at constant pressure of 400 $\mathrm{kPa}$ and flow rate of $200 \mathrm{ml} / \mathrm{min}$. Figure 5 shows oil rejection of the membranes as a function of operating time.

As can be seen, the oil rejection for the both membranes increased as a function of time due to the formation of cake layer [23]. In fact, the produced cake layer acts as an extra filtration layer. After about $100 \mathrm{~min}$ of the operation, a stable oil rejection of over $98 \%$ was observed for the blend PEI-CA hollow fiber membrane which 
can be related to the small pore sizes. The plain PEI membrane presented an approximate rejection of $94 \%$ after about 150 min of the operation which can be related to the larger pore sizes.

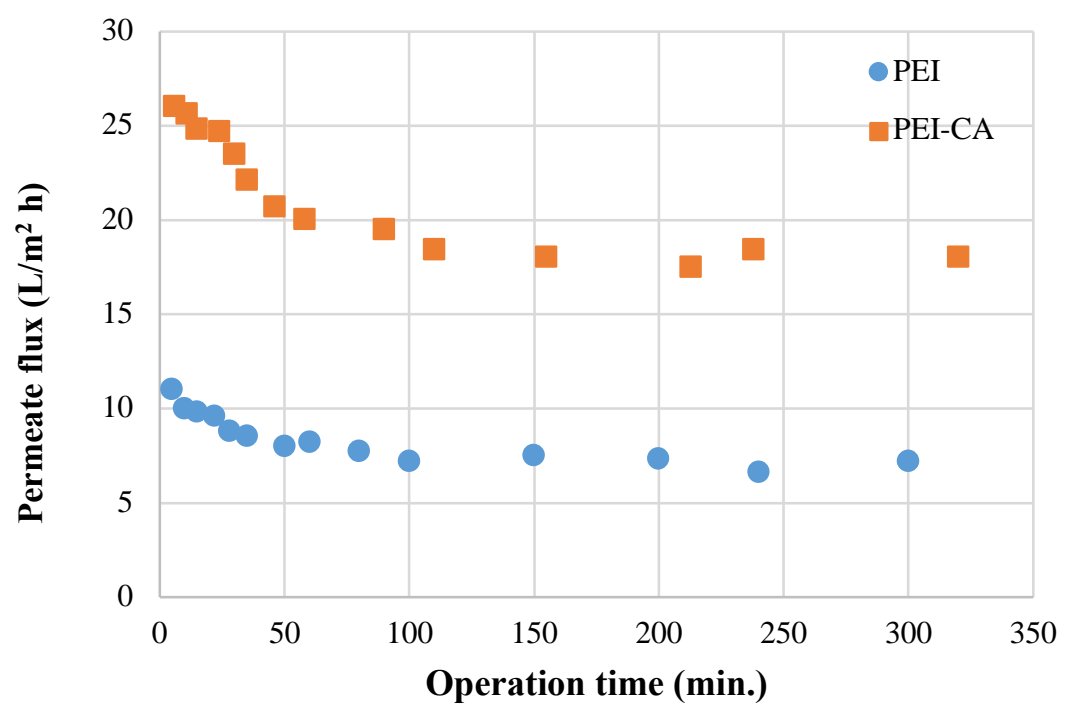

Figure 6 Permeation flux of the hollow fiber membranes

Table 4 Characteristics of the membranes after oil separation test

\begin{tabular}{lccc}
\hline $\begin{array}{l}\text { Hollow fiber } \\
\text { membrane }\end{array}$ & $\begin{array}{c}\mathbf{N}_{2} \text { permeance } \\
\text { @ 100 kPa } \\
(\mathbf{G P U})\end{array}$ & $\begin{array}{c}\text { Pure water flux } \\
\text { @ } \mathbf{4 0 0} \mathbf{~ k P a} \\
\left(\mathbf{L} / \mathbf{m}^{\mathbf{2}} \mathbf{h}\right)\end{array}$ & $\begin{array}{c}\text { Water } \\
\text { contact } \\
\text { angle }\left({ }^{\mathbf{o}}\right)\end{array}$ \\
\hline Used PEI & 6460 & 9.50 & $84.1 \pm 3.6$ \\
Used PEI-CA & 453 & 18.2 & $77.4 \pm 2.2$ \\
\hline
\end{tabular}

Although the oil droplets are larger than the mean pore size of the membranes, a small amount of the oil can be observed in the permeate side. This imperfect oil rejection could be related to the oil concentration at the outer surface of the membranes. It should be noted that concentration polarization can result in penetration of oil through the membrane pores at high operating pressure [24].

Figure 6 represents the water permeation flux of the membranes. The higher water flux of the blend PEICA membrane can be associated to the enhanced surface hydrophilicity and the open structure. In addition, the rate of reducing water flux for the blend membrane is moderately lower than the plain PEI membrane. The permeation flux of the plain PEI membrane reduced from $11.5 \mathrm{~L} / \mathrm{m}^{2} \mathrm{~h}$ to a stable value of about $8 \mathrm{~L} / \mathrm{m}^{2} \mathrm{~h}$, after $150 \mathrm{~min}$ of the separation operation. In the meantime, permeation flux of the blend PEI-CA membrane reduced from $26.5 \mathrm{~L} / \mathrm{m}^{2} \mathrm{~h}$ to a stable value of $18 \mathrm{~L} / \mathrm{m}^{2} \mathrm{~h}$, after $100 \mathrm{~min}$ of the operation. Therefore, it seems that the fouling rate of the blend membrane was smaller compared to the plain membrane. This can be a result of surface hydrophilicity improvement of the blend membrane.

In order to evaluate the stability of the membranes, the structure of the membranes used in the oil separation test for about $300 \mathrm{~min}$ was characterized and the results are given in Table 4. $\mathrm{N}_{2}$ permeance and pure water flux of the used membrane were relatively reduced compared to the 
fresh membranes which can be related to the pore blockage due to the fouling. However this effect is more serious for the plain PEI membrane. In addition, an increase in the water contact angle of the used membranes can confirm possible fouling of the membranes which affected the membranes surface structure.

Therefore, in order to achieve a cost-effective oil separation technology, it is necessary to develop the membrane structure in terms of having small pore size, good surface porosity, high hydrophilicity and low hydraulic resistance. By achieving these parameters, an improved oil rejection and water permeation flux can be reachable.

\subsection{CONCLUSION}

Hydrophilic CA was introduced into the PEI solution in order to enhance the membrane structure for oily wastewater treatment. FESEM, $\mathrm{N}_{2}$ permeation, water contact angle, water flux, and oil rejection tests were conducted to characterize the membranes structure. By addition of $\mathrm{CA}$, the blend membrane presented larger finger-likes morphology with a thicker outer skin layer. From $\mathrm{N}_{2}$ permeation test, the blend PEI-CA membrane showed a lower surface porosity $\left(697 \mathrm{~m}^{-1}\right)$ and mean pore size of $4.5 \mathrm{~nm}$. The higher water flux and lower hydraulic resistance of the blend PEI-CA membrane were related to the higher hydrophilicity and the open finger-like structure. Due to the improved structure of the blend PEICA membrane, a stable oil rejection of over $98 \%$ and the water flux of 18 $\mathrm{L} / \mathrm{m}^{2} \mathrm{~h}$ were achieved after $100 \mathrm{~min}$ of oil separation test. The prepared blend PEI-CA membrane with improved properties can potentially be used in treatment of oily wastewater for petrochemical and refinery industries

\section{REFERENCES}

[1] L. Yu, M. Han, F. He. 2017. A Review of Treating Oily Wastewater. Arab. J. Chem. 10: S1913-S1922.

[2] A. Mansourizadeh, A. Javadi Azad. 2014. Preparation of Blend Polyethersulfone/Cellulose Acetate/Polyethylene Glycol Asymmetric Membranes for OilWater Separation. J. Polym. Res. 21: 375-385.

[3] K. Scott. 2001. Crossflow Microfiltration of Water-in-oil Emulsions Using Corrugated Membranes. Sep. Purif. Technol. 22-23: 431-441.

[4] A. B. Koltuniewicz, R. W. Field, T. C. Arnot. 1995. Cross-flow and Dead-end Microfiltration of Oily-water Emulsion. Part I: Experimental Study and Analysis of Flux Decline. J. Membr. Sci. 102: 193-207.

[5] B. Chakrabarty, A. K. Ghoshal, M. K. Purkait. 2008. Ultrafiltration of Stable Oil-inwater Emulsion by Polysulfone Membrane. J. Membr. Sci. 325: 427-437.

[6] S. N. W. Ikhsan, N. Yusof, F. Aziz, N. Misdan, A. F. Ismail, W.-J. Lau, J. Jaafar, W. N. W. Salleh, N. H. H. Hairom. 2018. Efficient Separation of Oily Wastewater using Polyethersulfone Mixed Matrix Membrane Incorporated with Halloysite Nanotube-hydrous Ferric Oxide Nanoparticle. Sep. Purif. Technol. 199: 161-169.

[7] P. S. Goh, A. F. Ismail. 2018. A Review on Inorganic Membranes for Desalination and Wastewater 
Treatment. Desalination. 434: 60-80.

[8] N. M. Kocherginsky, C. L. Tan, W. F. Lu. 2003. Demulsification of Water-in-oil Emulsions via Filtration through a Hydrophilic Polymer Membrane. J. Membr. Sci. 220: 117-128.

[9] L. Li, L. Ding, Z. Tu, Y. Wan, D. Clausse, J.-L. Lanoisellé. 2009. Recovery of Linseed Oil Dispersed within an Oil-in-water Emulsion using Hydrophilic Membrane by Rotating Disk Filtration System. J. Membr. Sci. 342: 70-79.

[10] J. Zhoua, Q. Changa, Y. Wang, J. Wang, G. Meng. 2010. Separation of Stable Oil-water Emulsion by the Hydrophilic Nano-sized $\mathrm{ZrO}_{2}$ Modified $\mathrm{Al}_{2} \mathrm{O}_{3}$ Microfiltration Membrane. Sep. Purif. Technol. 75: 243-248.

[11] R. Mahendran, R. Malaisamy, D. R. Mohan. 2004. Cellulose Acetate and Polyethersulfone Blend Ultrafiltration Membranes. Part I: Preparation and Characterizations. Polym. Adv. Technol. 15: 149-157.

[12] K. Mu, D. Zhang, Z. Shao, D. Qin, Y. Wang, S. Wang. 2017. Enhanced Permeability and Antifouling Performance of Cellulose Acetate Ultrafiltration Membrane Assisted by L-Dopa Functionalized Halloysite Nanotubes. Carbohydr. Polym. 174: 688-696.

[13] A. El-Gendi, H. Abdallah, A. Amin, S. K. Amin. 2017. Investigation of Polyvinylchloride and Cellulose Acetate Blend Membranes for Desalination. J. Mol. Struct. 1146: 14-22.

[14] C. Lavanya, R. G. Balakrishna, K. Soontarapa, M. S. Padaki. 2019. Fouling Resistant Functional Blend Membrane for
Removal of Organic Matter and Heavy Metal Ions. J. Environ. Manag. 232: 372-381.

[15] Z. Sun, F. Chen. 2016. Hydrophilicity and Antifouling Property of Membrane Materials from Cellulose Acetate/Polyethersulfone in DMAc. Int. J. Biol. Macromol. 91: 143-150.

[16] M. Kumar, T. S. Rao, A. M. Isloor, G. P. Syed Ibrahim, Inamuddin, N. Ismail, A.F. Ismail, A. M. Asiri. 2019. Use of Cellulose

Acetate/Polyphenylsulfone

Derivatives to Fabricate Ultrafiltration Hollow Fiber Membranes for the Removal of Arsenic from Drinking Water. Int. J. Biol. Macromol. 129: 715727.

[17] A. Jayalakshmi, S. Rajesh, D. Mohan. 2012. Fouling Propensity and Separation Efficiency of Epoxidated Polyethersulfone Incorporated Cellulose Acetate Ultrafiltration Membrane in the Retention of Proteins. Appl. Surf. Sci. 258: 9770-9781.

[18] A. Rahimpour, S. S. Madaeni. $2007 . \quad$ Polyethersulfone (PES)/Cellulose Acetate Phthalate (CAP) Blend Ultrafiltrationmembranes:

Preparation, Morphology, Performance and Antifouling Properties. J. Membr. Sci. 305: 299-312.

[19] A. F. Ismail, I. R. Dunkinb, S. L. Gallivanb, S. J. Shilton. 1999. Production of Super Selective Polysulfone Hollow Fiber Membranes for Gas Separation. Polymer. 40: 6499-6506.

[20] J. M. S. Henis, M. K. Tripodi. 1981. Composite Hollow Fiber Membranes for Gas Separation: 
the Resistance Model Approach. J. Membr. Sci. 8: 233-246.

[21] L. P. Cheng. 1999. Effect of Temperature on the Formation of Microporous PVDF Membranes by Precipitation from 1octanol/DMF/PVDF and water/DMF/PVDF Systems. Macromolecules. 32: 6668-6674.

[22] E. Fontananova, J. C. Jansen, A. Cristiano, E. Curcio, E. Drioli. 2006. Effect of Additives in the Casting Solution on the
Formation of PVDF Membranes. Desalination. 192: 190-197.

[23] R. S. Faibish, Y. Cohen. 2001. Fouling-resistant Ceramicsupported Polymer Membranes for Ultrafiltration of Oil-InWater Microemulsions. $J$. Membr. Sci. 185: 129-143.

[24] P. Lipp, C. H. Lee, A. G. Fane, C. J. D. Fell. 1988. A Fundamental Study of the Ultrafiltration of Oil-water Emulsions. J. Membr. Sci. 36: 161-177. 